\title{
Adenocarcinosarcoma at the esophagogastric junction with long esophageal invasion: a case report
}

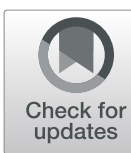

Kenichiro Furukawa', Masahiro Niihara', Takuya Kawata², Shuhei Mayanagi ${ }^{1}$ and Yasuhiro Tsubosa ${ }^{1 *}$ (D)

\begin{abstract}
Background: Carcinosarcoma of the esophagus or esophagogastric junction (EGJ) is a rare malignancy with both carcinomatous and sarcomatous components. There is no report of carcinosarcoma arising from the EGJ wherein the carcinomatous element was adenocarcinoma. We describe a patient with carcinosarcoma of the EGJ in which the carcinomatous element was adenocarcinoma.
\end{abstract}

Case presentation: A 52-year-old man was diagnosed with carcinoma on his EGJ after complaining of appetite loss. All tumor markers (carcinoembryonic antigen, squamous cell carcinoma antigen, alpha-fetoprotein, and carbohydrate antigen 19-9) were within the respective normal ranges. Esophagogastroduodenoscopy showed a 150-mm (100 mm esophageal side and $50 \mathrm{~mm}$ gastric side) type 1 tumor on his EGJ. A histopathological examination of a biopsy specimen revealed well-differentiated tubular adenocarcinoma at the gastric side; however, only necrotic tissue was noted on the esophageal side. Contrast-enhanced computed tomography did not reveal any invasion of the adjacent structures; however, it did show five swollen regional lymph nodes. ${ }^{18}$ F-Fluorodeoxyglucose positron emission tomography with computed tomography did not reveal distant metastases. We performed thoracic subtotal esophagectomy, total gastrectomy, and two-field plus left cervical paraesophageal lymphadenectomy. Macroscopically, the lesion consisted of two components: a 7.5-cm type 2 tumor and a 9-cm type 1 tumor at the proximal end of the type 2 tumor. Microscopically, the type 2 tumor showed predominantly solid or cribriform proliferation of tumor cells with clear cytoplasm, which was moderately differentiated adenocarcinoma with enteroblastic-like differentiation. The tumor cells of the adenocarcinoma component had periodic acid-Schiff (PAS)-positive globules and were positive for sal-like protein 4 (SALL 4) and negative for a-fetoprotein (AFP) or human epidermal growth factor receptor type 2 (HER2). The type 1 tumors consisted of the adenocarcinoma-like type 2 tumor and spindle cells (sarcomatous component). Part of the sarcomatous component showed cartilage differentiation. The type 2 and type 1 lesions were continuous lesions. The epicenter of the tumor was located at the EGJ. The adenocarcinoma component was present in 10 of 27 resected lymph nodes. The tumor was diagnosed as carcinosarcoma of the EGJ.

Conclusions: We report a rare patient with carcinosarcoma of the EGJ wherein the carcinomatous element was adenocarcinoma.

Keywords: Esophagus, Esophagogastric junction, Carcinosarcoma, Sarcomatoid carcinoma, Pseudosarcoma, Polypoid sarcoma, Adenocarcinoma

\footnotetext{
* Correspondence: y.tsubosa@scchr.jp

${ }^{1}$ Division of Esophageal Surgery, Shizuoka Cancer Center, 1007

Shimonagakubo, Nagaizumi-cho, Sunto-gun, Shizuoka 411-8777, Japan

Full list of author information is available at the end of the article
} 


\section{Background}

Carcinosarcoma of the esophagus or esophagogastric junction (EGJ) is a rare malignancy with both carcinomatous and sarcomatous components [1-3]. The carcinomatous part is generally squamous cell carcinoma (SCC) [1], and there have been no reports of carcinosarcoma arising from the EGJ wherein the carcinomatous element was adenocarcinoma. We herein report a patient with carcinosarcoma of the EGJ with long esophageal invasion wherein the carcinomatous element was adenocarcinoma.

\section{Case presentation}

A 52-year-old man was diagnosed with carcinoma on his EGJ following complaints of appetite loss. A histopathological examination of a biopsy specimen revealed adenosquamous carcinoma at a previous hospital. He was then referred to our hospital.

He had undergone appendectomy due to appendicitis at 13 years of age. He was an ex-smoker and drank $360 \mathrm{ml}$ of distilled spirits every day. His height and weight were $178.1 \mathrm{~cm}$ and $51.9 \mathrm{~kg}$, respectively. His body temperature was elevated to $38.5^{\circ} \mathrm{C}$. A hematologic examination showed inflammatory reaction (white blood cell $12430 / \mu \mathrm{L}$, neutrophil cell $86 \%$, and C-reactive protein $4.80 \mathrm{mg} / \mathrm{dL}$ ), mild renal disorder (blood urea nitrogen $26.8 \mathrm{mg} / \mathrm{dL}$ and creatinine $1.07 \mathrm{mg} / \mathrm{dL}$ ), and alkaline phosphatase elevation $(361 \mathrm{U} / \mathrm{L})$. All tumor markers (carcinoembryonic antigen, squamous cell carcinoma antigen, alpha-fetoprotein, and carbohydrate antigen 19-9) were within the respective normal ranges. Bacterial cultivation of the blood, sputum, and urine showed no obvious infectious findings.

Esophagogastroduodenoscopy showed a 150-mm (100 $\mathrm{mm}$ esophageal side and $50 \mathrm{~mm}$ gastric side) type 1 tumor on his EGJ that was obstructing the passage of food (Fig. 1). The epicenter of the tumor appeared to be on the esophagus. A histopathological examination of a biopsy specimen revealed well-differentiated tubular adenocarcinoma at the gastric side; however, only necrotic tissue was observed at the esophageal side. Endoscopically, there was no evidence of Barrett's esophagus.

Contrast-enhanced computed tomography did not reveal any invasion of the adjacent structures; however, five swollen regional lymph nodes were detected. ${ }^{18}$ F-Fluorodeoxyglucose positron emission tomography with computed tomography did not reveal distant metastases. We clinically diagnosed his tumor as advanced esophageal cancer, Lt Ae G, type 1, $150 \mathrm{~mm}$, well-differentiated tubular adenocarcinoma, cT3 N2 M0, cStage IIIB according to the Union for International Cancer Control TNM classification of malignant tumors, seventh edition (UICC-TNM 7th).

We performed video-assisted thoracic subtotal esophagectomy, open total gastrectomy, two-field plus left cervical paraesophageal lymphadenectomy, subcutaneous reconstruction using a free jejunal graft, and jejunostomy. The operation time was $8 \mathrm{~h}$ and $35 \mathrm{~min}$, and the estimated blood loss was $64 \mathrm{~mL}$. He experienced postoperative complications of grade IIIb anastomotic leakage, grade II pneumonitis, and grade I left recurrent laryngeal nerve paralysis according to the Clavien-Dindo classification [4], all of which improved with treatment, and he was discharged on post-operative day 24 .

Macroscopically, the lesion consisted of two components: a 7.5-cm type 2 tumor and a 9-cm type 1 tumor at the proximal end of the type 2 tumor (Fig. 2a). The type 2 tumor showed a white-gray cut surface, while the type 1 tumor showed the same white-gray cut surface with necrosis and hemorrhaging (Fig. 2b). Whether the epicenter of the lesion was at the gastric side or esophageal side was unclear, as most of the EGJ had been replaced by the tumor. Microscopically, the type 2 tumor was predominantly solid or cribriform proliferation of tumor cells with clear cytoplasm, which was moderately differentiated adenocarcinoma with enteroblastic-like differentiation (Fig. 2b, Fig. 3a). The tumor cells of the adenocarcinoma component had periodic acid-Schiff

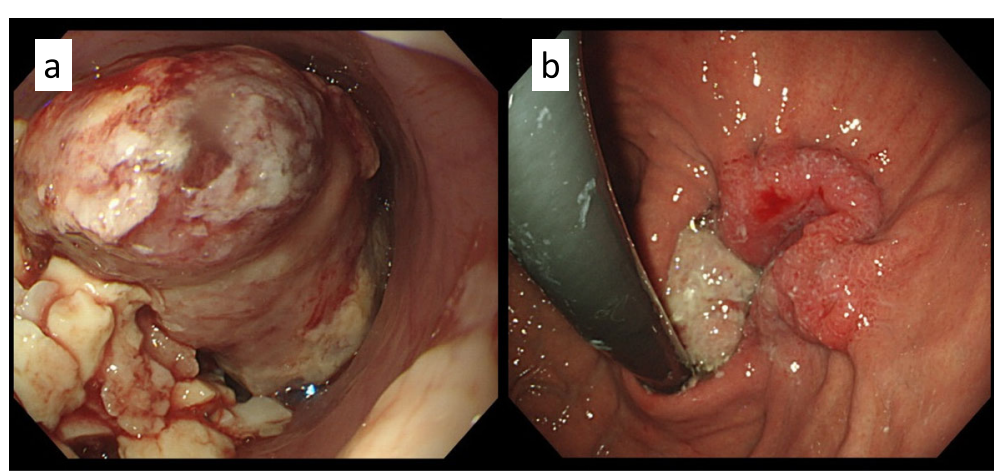

Fig. 1 Findings of esophagogastroduodenoscopy. a Esophageal side, b gastric side. Esophagogastroduodenoscopy showed a 150-mm (100 mm esophageal side and $50 \mathrm{~mm}$ gastric side) type 1 tumor at the esophagogastric junction obstructing the passage of food. The epicenter of the tumor appeared to be on the esophagus 


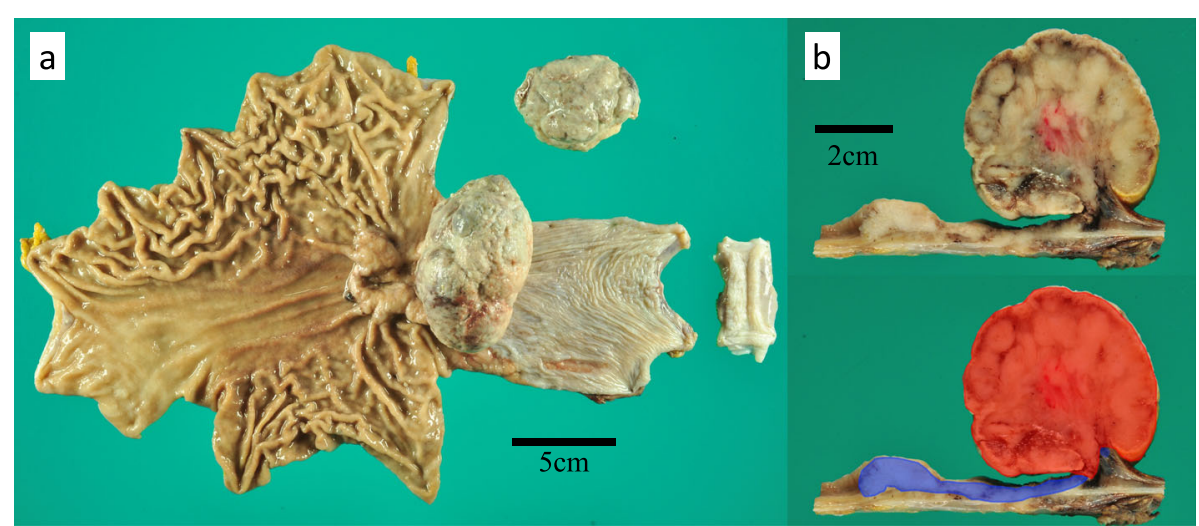

Fig. 2 Macroscopic findings of the resected specimen and distribution of the carcinomatous and sarcomatous components. a The lesion consisted of two components: a 7.5-cm type 2 tumor and a 9-cm type 1 tumor at the proximal end of the type 2 tumor. We also observed a 6$\mathrm{cm}$ mass of tumor tissue that appeared to be separate from the type 1 tumor. $\mathbf{b}$ The type 2 tumor showed a white-gray cut surface, while the type 1 tumor showed the same white-gray cut surface with necrosis and hemorrhaging. The blue areas indicate the carcinomatous component, and the red area shows the carcinomatous with sarcomatous components

(PAS)-positive globules and were positive for sal-like protein 4 (SALL 4) and negative for $\alpha$-fetoprotein (AFP) or human epidermal growth factor receptor type 2 (HER2) (Fig. 3b-e). The reasons why enteroblastic-like differentiation was considered to have occurred were as follows: the tumor cells had clear cytoplasm, while they were also PAS-positive and SALL 4-positive. The type 1 tumors consisted of adenocarcinoma, like the type 2 tumor, which was positive for SALL 4, and spindle cells (sarcomatous component) growing mainly in the submucosal layer (Fig. 2b, Fig. 4a, b). There was no obvious SCC component in the type 1 tumor. Part of the sarcomatous component showed cartilage differentiation (Fig. 4c). The type 2 and type 1 lesions were continuous lesions, and there were smooth transitional features between the two lesions. The epicenter of the tumor was at the EGJ. The deepest invasive site was associated with the type 2 tumor, which showed invasion to the subserosa. The horizontal and vertical margins were negative for tumor cells. Histologically, there was no evidence of

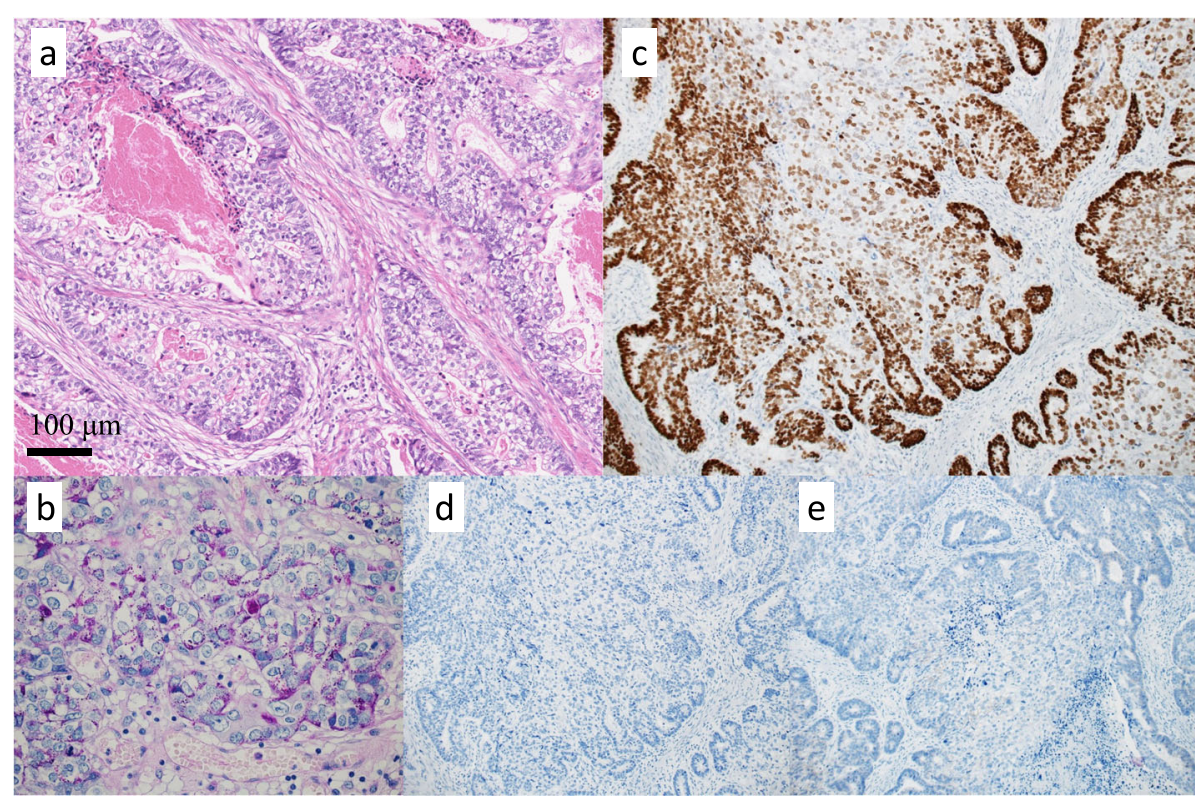

Fig. 3 Microscopic findings of the type 2 tumor. a The type 2 tumor predominantly showed solid or cribriform proliferation of tumor cells with clear cytoplasm, which was moderately differentiated adenocarcinoma with enteroblastic-like differentiation (hematoxylin-eosin staining). The tumor cells of the adenocarcinoma component had periodic acid-Schiff (PAS)-positive globules (b) and were positive for sal-like protein 4 (SALL 4) (c) and negative for a-fetoprotein (AFP) (d) and human epidermal growth factor receptor type 2 (HER2) (e) 


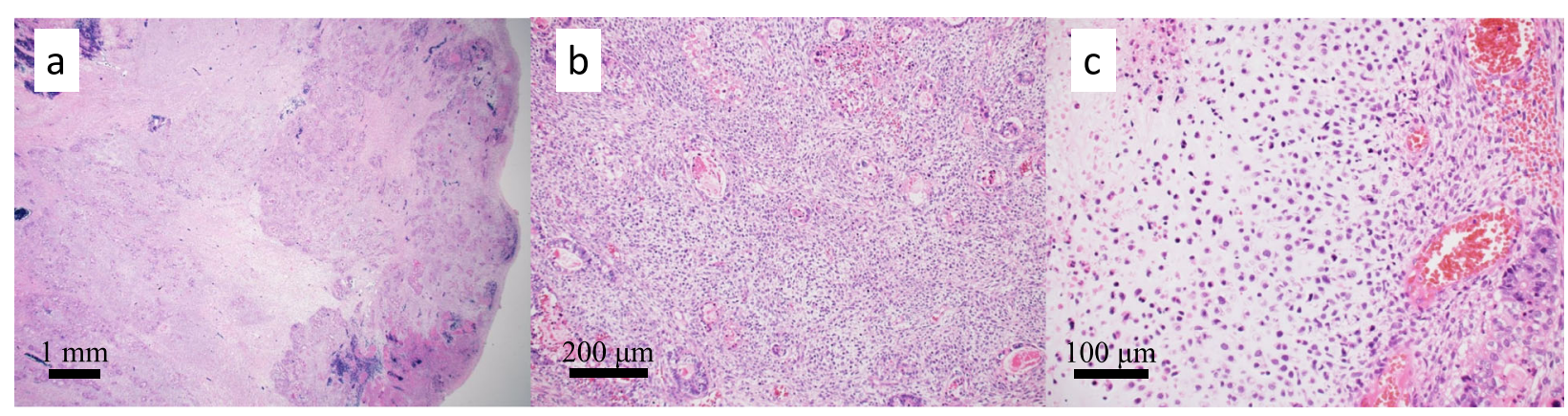

Fig. 4 Microscopic findings of the type 1 tumors. Hematoxylin-eosin staining. a, b The type 1 tumors consisted of adenocarcinoma, like the type 2 tumor, and spindle cells. c Part of the sarcomatous component showed cartilage differentiation

Barrett's esophagus in the resected specimen. We observed all resected esophagus specimens with a cutting width of approximately $10 \mathrm{~mm}$. The adenocarcinoma component was present in 10 of 27 resected lymph nodes. The tumor was finally diagnosed as carcinosarcoma of the EGJ with a carcinomatous component of adenocarcinoma, Siewert type II, type $1+2,110 \mathrm{~mm}$, pT3 N3 M0, pStage IIIC according to UICC-TNM 7th.

The patient underwent adjuvant systemic chemotherapy with S-1 for gastric adenocarcinoma but developed paraaortic lymph node metastases 5 months after surgery.

\section{Discussion}

Carcinosarcoma of the esophagus is rare and is also referred to as spindle cell carcinoma, sarcomatoid carcinoma, pseudosarcomatous SCC, polypoid carcinoma, metaplastic carcinoma, SCC with spindle-cell component, and carcinoma with mesenchymal stroma $[5,6]$. The incidence of such tumors has been reported to be 0.4 to $2.4 \%$ among all esophageal neoplasms [5, 7-10].

The carcinomatous part of esophageal carcinosarcoma generally consists of an SCC [1]. We found only two patients reported as having carcinosarcoma of esophagus wherein the carcinomatous component was adenocarcinoma [1, 8]. Dworak reported a patient with carcinosarcoma in Barrett's esophagus [1], and Zhang reported 71 patients with esophageal carcinosarcoma in which one patient had a carcinomatous component of adenocarcinoma [8]. In our patient, there was no obvious SCC component.

Carcinosarcoma of the EGJ is extremely rare. We found only one case report of carcinosarcoma arising from the EGJ [3]. The patient was diagnosed with carcinosarcoma because the tumor cells were positive for both cytokeratin and vimentin. The type of carcinoma was unknown because the tumor cells were a single and uniform population of spindle-shaped cells, and immunohistochemical staining was not performed to determine the carcinoma type. Therefore, this is the first report describing carcinosarcoma of the EGJ whose carcinomatous component was adenocarcinoma. Furthermore, although most cases of adenocarcinoma of the EGJ arise from Barrett's esophagus $[11,12]$, there was no evidence of Barrett's esophagus endoscopically or histologically in our patient.

In general, esophageal carcinosarcoma presents as an intraluminal polypoid mass located in the middle and lower thoracic esophagus. Therefore, if a polypoid tumor is observed on EGJ and the result of a biopsy is not typical adenocarcinoma or SCC, we should consider the possibility of carcinosarcoma.

The polypoid appearance results in an early onset of symptoms and thus an earlier diagnosis and treatment. Although esophageal carcinosarcoma is more likely to be diagnosed at an early $\mathrm{T}$ stage, it carries a highly aggressive potential for lymph node metastasis $[7,8,13]$. The carcinomatous component metastasizes to the lymph node more often than the sarcomatous component [7]. In our patient, unfortunately, the carcinosarcoma invaded toward the adventitia, and only the carcinomatous component was found to have metastasized to resected lymph nodes, as in previous report.

Immunohistochemical staining can help clarify how carcinosarcoma develops. Specifically, it appears that adenocarcinoma with enteroblastic-like differentiation differentiated to mesenchymal cells, including cartilage cells, the present case.

The tumor in our patient may have been gastric cancer with esophageal invasion, as most of the EGJ had been replaced by the tumor, and the epicenter of the tumor was unclear. Regarding gastric carcinosarcoma, there have been 38 patients reported in the English literature [14-46]. Among them, there was only one patient whose tumor had invaded the esophagus and no patients whose tumor has enteroblastic-like differentiation [39]. However, some reports did not mention the extent of esophageal invasion or details concerning the carcinoma component.

\section{Conclusion}

We herein report a rare case of carcinosarcoma of the EGJ with long esophageal invasion wherein the carcinomatous element was adenocarcinoma. 


\section{Abbreviations}

EGJ: Esophagogastric junction; SCC: Squamous cell carcinoma; UICC-TNM 7th: Union for international cancer control TNM classification of malignant tumors seventh edition

\section{Acknowledgements \\ Not applicable}

\section{Authors' contributions}

KF, MN, TK, and YT wrote the manuscript. TK diagnosed the disease histopathologically. MN and SM participated in the design of the study. All authors read and approved the final manuscript.

\section{Authors' information}

Not applicable

\section{Funding}

Not applicable

\section{Availability of data and materials}

Not applicable

\section{Ethics approval and consent to participate}

Not applicable

\section{Consent for publication}

Written informed consent was obtained from the patient for the publication of this case report and any accompanying images. A copy of the written informed consent is available for review by the Editor-in-Chief of this journal.

\section{Competing interests}

The authors declare that they have no competing interests.

\section{Author details}

${ }^{1}$ Division of Esophageal Surgery, Shizuoka Cancer Center, 1007 Shimonagakubo, Nagaizumi-cho, Sunto-gun, Shizuoka 411-8777, Japan. 2Division of Pathology, Shizuoka Cancer Center, 1007 Shimonagakubo, Nagaizumi-cho, Sunto-gun, Shizuoka 411-8777, Japan.

\section{Received: 9 November 2019 Accepted: 6 January 2020}

\section{Published online: 20 January 2020}

\section{References}

1. Dworak O, Koerfgen HP. Carcinosarcoma in Barrett's oesophagus: a case report with immunohistological examination. Virchows Arch A Pathol Anat Histopathol. 1993:422:423-6.

2. Japan Esophageal Society. Japanese Classification of Esophageal Cancer, 11th Edition: part II and III. Esophagus. 2017;14:37-65.

3. Solerio D, Ruffini E, Camandona M, Raggio E, Castellano I, Dei PM. Carcinosarcoma of the esophagogastric junction. Tumori. 2008:94:416-8.

4. Dindo D, Demartines N, Clavien PA. Classification of surgical complications: a new proposal with evaluation in a cohort of 6336 patients and results of a survey. Annals of surgery. 2004;240:205-13.

5. Kuo CJ, Lin TN, Lin CJ, Wu RC, Chang HK, Chu YY, et al. Clinical manifestation of esophageal carcinosarcoma: a Taiwan experience. Dis Esophagus. 2010;23:122-7.

6. Bosman FT, Carneiro F, Hruban RH, Theise ND. WHO Classification of Tumours of the Digestive System. 4th ed. Lypn: IARC Press; 2010.

7. Iyomasa $\mathrm{S}$, Kato $\mathrm{H}$, Tachimori $\mathrm{Y}$, Watanabe $\mathrm{H}$, Yamaguchi $\mathrm{H}$, Itabashi $\mathrm{M}$. Carcinosarcoma of the esophagus: a twenty-case study. Jpn J Clin Oncol. 1990;20:99-106

8. Zhang B, Xiao Q, Yang D, Li X, Hu J, Wang Y, et al. Spindle cell carcinoma of the esophagus: A multicenter analysis in comparison with typical squamous cell carcinoma. Medicine (Baltimore). 2016;95:e4768.

9. Xu LT, Sun CF, Wu LH, Chang ZR, Liu TH. Clinical and pathological characteristics of carcinosarcoma of the esophagus: report of four cases. Ann Thorac Surg. 1984;37:197-203.

10. Gal AA, Martin SE, Kernen JA, Patterson MJ. Esophageal carcinoma with prominent spindle cells. Cancer. 1987;60:2244-50.
11. Cameron AJ, Lomboy CT, Pera M, Carpenter HA. Adenocarcinoma of the esophagogastric junction and Barrett's esophagus. Gastroenterology. 1995; 109:1541-6.

12. Mendes de Almeida JC, Chaves P, Pereira AD, Altorki NK. Is Barrett's esophagus the precursor of most adenocarcinomas of the esophagus and cardia? A biochemical study. Ann Surg. 1997;226:725-33 discussion 33-5.

13. Sanada Y, Hihara J, Yoshida K, Yamaguchi Y. Esophageal carcinosarcoma with intramural metastasis. Dis Esophagus. 2006;19:119-31.

14. Kikuyama R, Tanaka K, Tano S, Iguchi T, Nishikawa K, Harada T, et al. A case of gastric carcinosarcoma. Endoscopy. 2009;41(Suppl 2):E220-1.

15. Tsuneyama K, Sasaki M, Sabit A, Yokoi K, Arano Y, Imai T, et al. A case report of gastric carcinosarcoma with rhabdomyosarcomatous and neuroendocrinal differentiation. Pathol Res Pract. 1999:195(2):93-7 discussion 8.

16. Yamazaki K. A gastric carcinosarcoma with neuroendocrine cell differentiation and undifferentiated spindle-shaped sarcoma component possibly progressing from the conventional tubular adenocarcinoma; an immunohistochemical and ultrastructural study. Virchows Arch. 2003;442(1): 77-81.

17. Teramachi K, Kanomata N, Hasebe T, Ishii G, Sugito M, Ochiai A Carcinosarcoma (pure endocrine cell carcinoma with sarcoma components) of the stomach. Pathol Int. 2003;53(8):552-6.

18. Bansal M, Kaneko M, Gordon RE. Carcinosarcoma and separate carcinoid tumor of the stomach. A case report with light and electron microscopic studies. Cancer. 1982;50(9):1876-81.

19. Kuroda H, Saito H, Kono Y, Murakami Y, Shishido Y, Matsunaga T, et al. Carcinosarcoma of stomach confined to the mucosa. Yonago Acta Med. 2017:60(4):246-50.

20. Choi KW, Lee WY, Hong SW, Chang YG, Lee B, Lee HK. Carcinosarcoma of the stomach: a case report. J Gastric Cancer. 2013;13(1):69-72.

21. Randjelovic T, Filipovic B, Babic D, Cemerikic V, Filipovic B. Carcinosarcoma of the stomach: a case report and review of the literature. World J Gastroenterol. 2007;13(41):5533-6.

22. Kayaselcuk F, Tuncer I, Toyganozu Y, Bal N, Ozgur G. Carcinosarcoma of the stomach. Pathol Oncol Res. 2002;8(4):275-7.

23. Selcukbiricik F, Tural D, Senel ET, Dervisoglu S, Serdengecti S. Gastric carcinoma with osteoblastic differentiation. Int J Surg Case Rep. 2012;3(11): $516-9$

24. Ikeda Y, Kosugi S, Nishikura K, Ohashi M, Kanda T, Kobayashi T, et al. Gastric carcinosarcoma presenting as a huge epigastric mass. Gastric Cancer. 2007; 10(1):63-8.

25. Nakayama Y, Murayama H, Iwasaki H, Iwanaga S, Kikuchi M, Ikeda S, et al. Gastric carcinosarcoma (sarcomatoid carcinoma) with rhabdomyoblastic and osteoblastic differentiation. Pathol Int. 1997:47(8):557-63.

26. Kuroda N, Oonishi K, Iwamura S, Ohara M, Hirouchi T, Mizumo K, et al. Gastric carcinosarcoma with neuroendocrine differentiation as the carcinoma component and leiomyosarcomatous and myofibroblastic differentiation as the sarcomatous component. APMIS. 2006;114(3):234-8.

27. Fujiie M, Yamamoto M, Taguchi K, Iwanaga A, Ohgaki K, Egashira A, et al. Gastric carcinosarcoma with rhabdomyosarcomatous differentiation: a case report and review. Surg Case Rep. 2016;2(1):52.

28. Sato Y, Shimozono T, Kawano S, Toyoda K, Onoe K, Asada Y, et al. Gastric carcinosarcoma, coexistence of adenosquamous carcinoma and rhabdomyosarcoma: a case report. Histopathology. 2001;39(5):543-4

29. Cirocchi R, Trastulli S, Desiderio J, Grassi V, Barillaro I, Santoro A, et al. Gastric carcinosarcoma: a case report and review of the literature. Oncol Lett. 2012; 4(1):53-7.

30. Matsukuma S, Wada R, Hase K, Sakai Y, Ogata S, Kuwabara N. Gastric stump carcinosarcoma with rhabdomyosarcomatous differentiation. Pathol Int. 1997:47(1):73-7.

31. Nie L, Zhou X, Peng L, Fu Y, Cheng Y, Huang Q. Histological heterogeneity and distributional difference of gastric carcinosarcoma: report of 4 cases and literature review. Pol J Pathol. 2018;69(4):366-75

32. Xu F, Zou WB, Li XP, Xu YM, Qi XF, Hu LH, et al. Multiple carcinosarcomas of the esophagus and stomach. Oncol Lett. 2013;5(3):1017-21.

33. Gohongi T, lida H, Gunji N, Orii K, Ogata T. Postsurgical radiation therapy for gastric carcinosarcoma with c-kit expression: a case report. World J Gastroenterol. 2015;21(9):2830-5.

34. Yoshida H, Tanaka N, Tochigi N, Suzuki Y. Rapidly deforming gastric carcinosarcoma with osteoblastic component: an autopsy case report. World J Gastroenterol. 2012;18(30):4064-8. 
35. Sato A, Oki E, Kohso H, Endo Y, Uchida H, Hiroshige S, et al. Sarcomatoid carcinoma of the remnant stomach: report of a case. Surg Today. 2013;43(3): 308-12.

36. Robey-Cafferty SS, Grignon DJ, Ro JY, Cleary KR, Ayala AG, Ordonez NG, et al. Sarcomatoid carcinoma of the stomach. A report of three cases with immunohistochemical and ultrastructural observations. Cancer. 1990;65(7): 1601-6.

37. Bekki T, Fujikuni N, Tanabe K, Yonehara S, Amano H, Noriyuki T, et al. The gastric carcinosarcoma with severe venous invasion: a case report. Surg Case Rep. 2018;4(1):14.

38. Cho KJ, Myong NH, Choi DW, Jang JJ. Carcinosarcoma of the stomach. A case report with light microscopic, immunohistochemical, and electron microscopic study. APMIS. 1990;98(11):991-5.

39. Dundas SA, Slater DN, Wagner BE, Mills PA. Gastric adenocarcinoleiomyosarcoma: a light, electron microscopic and immunohistological study. Histopathology. 1988;13(3):347-50.

40. Melato M, Bucconi S, Grillo BP, Angelucci D, Di Stefano P, Natoli C. Carcinosarcoma and separate neuroendocrine malignant tumor of a malignancy promoter, the gastric stump. Anticancer Res. 1993;13(6b):2485-8.

41. Cruz JJ, Paz JI, Cordero M, Martin J, del Mar Abad M. Carcinosarcoma of the stomach with endocrine differentiation. A case report. Tumori. 1991;77(4): 355-7.

42. Siegal A, Freund U, Gal R. Carcinosarcoma of the stomach. Histopathology. 1988;13(3):350-3.

43. Tanimura H, Furuta M. Carcinosarcoma of the stomach. Am J Surg. 1967; 113(5):702-9.

44. Arganaras E, Rigdon RH. Carcinosarcoma of the stomach. Gastroenterology. 1963:44:322-9.

45. Hanada M, Nakano K, li Y, Takami M. Carcinosarcoma of the stomach. A case report with light microscopic, immunohistochemical, and electron microscopic study. Acta Pathol Jpn. 1985;35(4):951-9.

46. Tokunaga O, Morimatsu M, Nakashima T. Collision tumor of the stomach with carcinosarcoma and tubulo-papillary adenocarcinoma. Acta Pathol Jpn. 1979;29(5):819-24

\section{Publisher's Note}

Springer Nature remains neutral with regard to jurisdictional claims in published maps and institutional affiliations.

\section{Submit your manuscript to a SpringerOpen ${ }^{\circ}$ journal and benefit from:}

- Convenient online submission

- Rigorous peer review

- Open access: articles freely available online

- High visibility within the field

- Retaining the copyright to your article

Submit your next manuscript at $\boldsymbol{\nabla}$ springeropen.com 